\title{
Reactive Attention: Video Surveillance in Berlin Shopping Malls
}

\author{
Frank Helten and Bemd Fischer1
}

\begin{abstract}
The paper examines the practice of use of video-surveillance in Berlin Shopping Malls. The video systems observed here do not seem to be an efficient instrument of social control and exclusion. They are used more on demand for various purposes such as the monitoring of daily tasks and the co-ordination of persons working inside the mall. The objectives publicly claimed by management - crime prevention and the like could not be achieved because the everyday practice presents other tasks to the operators. The workplace, the personnel, their multiple tasks, their qualifications support more a reactive use of video surveillance than a proactive targeted observation of individuals, even if the equipment would allow for that. It may turn out that the CCTV infrastructure of Berlin shopping malls can be characterised best as test-beds - open for various applications. There are, however, obstacles to this in the form of data protection concerns and the lack of political and economic support to go further (tied of course to financial constraints). Finally, as shown in our study, the social practice in everyday life continues to resist one-dimensional expectations of the technological possibilities of CCTV.
\end{abstract}

\section{Introduction}

Today it appears that the old-European mode of surveillance based on agent's eyes and sometimes ears have been complemented by powerful and anonymous surveillance technology. Recent blunt and rapid social transformations, triggered by economic and industrial decay together with rapid technological innovations, turbo capital driven insecurity about the future, have changed things. While Giddens pointed out that modernisation and rationalisation are always accompanied by a growth of surveillance (Giddens, 1987), some social scientists are now talking about the coming of 'surveillance society' (Lyon 1994). Developments in the UK and US, in fact, illustrate that the infrastructure and devices for surveillance represent a field of growing public and private interest (Stanley and Steinhardt, 2003) - and the rise of a more or less private-public network of control. There seems to be no escaping ever increasing surveillance.

\footnotetext{
${ }^{1}$ Berliner Institut für Sozialforschung (Berlin Institute for Social Research), Germany. mailto:f.helten@bis berlin.de
} 
Political actors have started to explore the various ways in which this network of control can fight crime and lower risks. One example: London's video-monitored ring of steel was first conceived as a safeguard against IRA terrorists. Today additional purposes have been invented: The same infrastructure serves to control access by car (Schubert, 2003: 13). This control and surveillance mode seems to be a model of how urban space will be used in the future: permission to enter depends on payment (see Graham and Marvin, 2001). Money is not, of course, the only means to filter out unwanted persons. The multipurpose character of surveillance technology, may lead to new and not very user-friendly applications. In the near future, it will be possible to apply not only video surveillance and related recognition software, but also new identification and positioning devices that inform the stakeholders of the surveillance society as to what the now transparent man or woman is doing. The industrial security complex - as new hope of the global economy - is actively pursuing this goal by building up new infrastructures and modes of control. In Germany there is an ongoing critical debate on the deployment of CCTV in public spaces. However private space and the private sector seem not to be very impressed by this discussion. On the contrary, the privately owned publicly accessible space is the place where CCTV in Germany takes place. In the following we want to explore some modules of the hereto related infrastructure that may in the future represent the privately owned foundations of a surveillance society.

We aim to show first how surveillance works as a process of spatialisation. Our intention is to demonstrate how the 'invisible hand' - understood as a more or ess anonymous actor proceeds in a unplanned and incremental way to realise something which could be identified as the self-organisation of surveillance in publicly accessible space as an ecology of surveillance. Since video surveillance of public urban space in Berlin is rather the exception, we decided to concentrate on video surveillance ${ }^{2}$ in shopping malls with regard to location and quality of urban space, accessibility, surface, etc.

We then analyse the everyday practice of video surveillance within malls in order to determine whether or not existing surveillance potentials pose a threat to freedom and everyday urban behaviour. Here we present some of our findings from fieldwork, including observation in the control room, interviews with control staff, and some heuristic experiments inside shopping malls ${ }^{3}$. In the final section we discuss our observations and indicate possible future trends of video surveillance in urban space.

\section{Ecology of Surveillance: Outcomes of a socio-geographical survey in Berlin}

The shopping malls of today are hybrids as they contain traces of the passage, the department store, and the supermarket in its architecture, spatial organisation, and variety of opportunities

\footnotetext{
${ }^{2}$ Frank Helten \& Bernd Fischer 2003: A survey of Berlin Shopping Malls. Unpublished . Berlin: Berliner Institut für Sozia lforschung

${ }^{3}$ Our research on video-surveillance in Berlin shopping malls is based on interviews with centre managers, security managers and operators, on-site flashlight observations, in-depth observations in two control rooms, heuristic experiments at various sites.
} 
for consumption and amusement, to see and be seen. Today's malls are new focal points of urbanity: meeting points, community centres, entertainment areas, even tourist attractions. It is thus difficult to define a shopping mall as we can differentiate in terms of the functions provided, services and products offered, surface space, etc. For this reason, we decided to define the shopping mall pragmatically, concentrating on the characteristics of the building, the number of shops, and the applied business model. Shopping malls represent integrated and covered larger complexes of buildings with a multitude of business actors, hosting various activities and managed by one shopping-mall company in either the trade or financial sector ${ }^{4}$. According to this definition, we identified a total of 62 shopping malls: 35 in Berlin East and 27 in Berlin West, distributed in space as shown in Figure 1. Overall there is considerable development stretching from the western part of the city to the Northeast. There is also a clear alignment of shopping malls along the so-called S-Bahn Ring (rapid urban rail circle). We also see a concentration in the business districts of both City West and City East, and an insertion of shopping malls into the business structure of the main streets in more residential areas. Table 1 presents the video surveillance infrastructure of all shopping malls surveyed. Nearly $60 \%$ of all malls have video surveillance. There is a clear preponderance of video-monitored shopping malls in eastern Berlin.

\begin{tabular}{|l|l|l|l|l|}
\hline Shopping Malls & \multicolumn{2}{|l|}{$\begin{array}{l}\text { Berlin East } \\
\text { abs }\end{array}$} & \multicolumn{2}{|l|}{ Berlin West } \\
\hline abs
\end{tabular}

Table 1: East-West Differentiation of Shopping Malls with and without Video Surveillance

Eastern and western Berlin differ both in the frequency of shopping malls and the presence of video surveillance. Nearly $2 / 3$ of all shopping malls in eastern Berlin are under video surveillance, with a slight preponderance of video surveillance along the suburban fringe. In western Berlin, slightly more than $1 / 3$ of all shopping malls have video surveillance, concentrated in the inner urban districts.

\begin{tabular}{|l|l|l|}
\hline Accessibility & abs & $\%$ \\
\hline Underground, Urban Rail, Tram & 39 & 62.9 \\
\hline Pedestrian/ Bus/ Car & 19 & 30.6 \\
\hline Car or Bus & 4 & 6.5 \\
\hline Total & 62 & 100 \\
\hline
\end{tabular}

Table 2: Accessibility of Shopping Malls

In addition to this spatial pattern, it is also useful to explore the locational structure of shopping malls in terms of their accessibility and the type of catchment areas. Table 2 shows the kinds of urban transportation connected to shopping malls. Nearly $2 / 3$ of malls are accessible by mass urban transportation such as underground, tram, or rapid urban rail. Another $30 \%$ are located

\footnotetext{
${ }^{4}$ Adapted from International Council of Shopping Centers, New York, which defines the shopping centre as follows: "A group of retail or other commercial establishments that is planned, developed, owned and managed as a single property. On-site parking is provided. The center's size and orientation are generally determined by the market characteristics of the trade area served by the center. The two main configurations of shopping centers are malls and open-air strip centers." (quoted in Falk 2003)
} 
within walking distance - the malls within the inner urban districts - and can also be reached by bus and car. Less than $7 \%$ of all malls are accessible only by car or bus. Most are situated outside the suburban fringe and are attractive only to those with their own cars.

Most shopping malls that can be reached by underground, tram, or rapid urban rail offer a direct or integrated access to public transportation. Such malls widely employ video surveillance. Table 3 shows the relation between accessibility of malls and video surveillance. Approximately $3 / 4 \mathrm{of}$ all shopping malls with video surveillance are located close to convenient urban mass transportation.

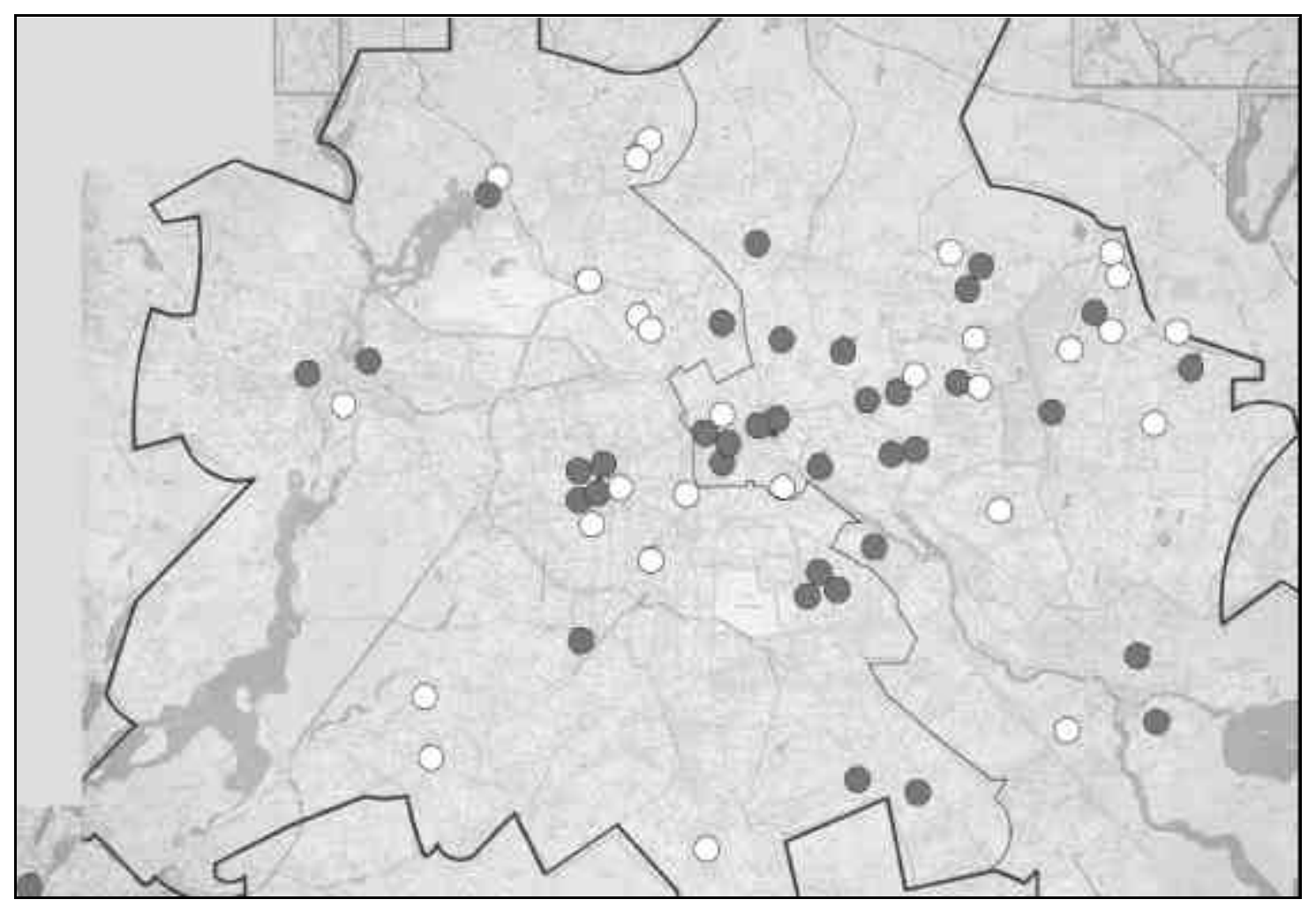

O Shopping mall with CCTV

O Shopping mall without CCTV

1. Municipal border of Berlin

Former East-West border (Berlin Wa II)

Figure 1: Distribution of Berlin Shopping Malls

(So urc e: own survey; map basis: Mairs Geographischer Verlag 2002)

\begin{tabular}{|l|l|l|}
\hline Video surveillance & abs & $\%$ \\
\hline Underground , Urban Rail, Tram & 25 & 71.4 \\
\hline Pedestrian/ Bus/ Car & 8 & 22.9 \\
Car or Bus & 2 & 5.7 \\
\hline Total & 35 & 100 \\
\hline
\end{tabular}

Table 3: Accessibility of Shopping Malls/Video surveillance 
By catchment area we understand a differentiation with regard to the products and services offered by shopping malls and the number of customers they attract. Some shopping malls, such as the neighbourhood centre, address only the everyday needs of the visitor. Other types, such as the super regional centre, cover an extended range of consumer goods. The most frequent shopping mall types in term of catchment areas are the neighbourhood centre and the local centre, which address the everyday needs of the consumer. In terms of video surveillance, we find that the regional centre and super-regional centre have a much higher level of video surveillance equipment than the neighbourhood and local centre (Table 4).

\begin{tabular}{|l|l|ll|l|l|l|}
\hline Catchment Area & Video & \multicolumn{3}{l|}{ Without Video } & \multicolumn{1}{l|}{ Total } \\
\hline & $\mathrm{n}$ & $\%$ & $\mathrm{n}$ & $\%$ & $\mathrm{n}$ & $\%$ \\
\hline $\begin{array}{l}\text { Neighbourhood } \\
\text { Centre }\end{array}$ & 9 & 37.5 & 15 & 62.5 & 24 & 100 \\
\hline Local Centre & 9 & 47.3 & 10 & 52.6 & 19 & 100 \\
\hline Regional Centre & 10 & 90.0 & 1 & 10.0 & 11 & 100 \\
\hline Super-regional centre & 3 & 75.0 & 1 & 25.0 & 4 & 100 \\
\hline Other & 4 & 100 & - & - & 4 & 100 \\
\hline
\end{tabular}

Table 4: Catchment Area and Video Surveillance

This finding confirms the assumption that the broader the range of products and services offered by shopping malls, and the greater their surface, the more likely they are to employ CCTV which facilitates the management. We next compare this result with the distribution of malls inside different areas of urban social development. According to three distinct urban zones, Table 5 shows the distribution of shopping malls in relation to the use of video surveillance.

\begin{tabular}{|l|l|l|l|l|l|l|}
\hline & \multicolumn{2}{|l|}{ Video } & \multicolumn{2}{l|}{ Without Video } & \multicolumn{2}{l|}{ Total } \\
\hline $\begin{array}{l}\text { Urban Social } \\
\text { Development }\end{array}$ & $\mathrm{n}$ & $\%$ & $\mathrm{n}$ & $\%$ & $\mathrm{n}$ & $\%$ \\
\hline Stable Development & 20 & 58.8 & 14 & 41.2 & 34 & 100 \\
\hline Some Problems & 8 & 57.1 & 6 & 42.8 & 14 & 100 \\
\hline PemanentProblems & 7 & 50 & 7 & 50 & 14 & 100 \\
\hline Total & 35 & & 27 & & 62 & \\
\hline
\end{tabular}

Table 5: Quality of Urban Social Development ${ }^{5}$ and Shopping Malls

There is a considerable frequency of video surveillance in urban areas with a stable and normal development. In comparison to more problematic areas, differences are minor. But they cast doubt on the assumption that video surveillance is mainly used to ensure a secure atmosphere for shopping in problematic areas.

Table 6 reflects a shift in urban reconstruction dating from the 1990s: the effort to implant shopping malls inside problematic urban areas and slightly more than every second other shopping mall in such areas is under video surveillance.

\footnotetext{
5 Categories and definitions: Senatsverwaltung für Stadtentwicklung, Umweltschutz und Technologie, Berlin (1998) 


\begin{tabular}{|l|l|l|l|l|l|l|l|l|}
\hline & \multicolumn{2}{|l|}{$\begin{array}{l}\text { Stable } \\
\text { Development }\end{array}$} & \multicolumn{2}{l|}{$\begin{array}{l}\text { Some } \\
\text { Problems }\end{array}$} & \multicolumn{2}{l|}{$\begin{array}{l}\text { Pemanent } \\
\text { Problems }\end{array}$} & \multicolumn{2}{l|}{ Total } \\
\hline Year of Opening & a bs & $\%$ & a bs & $\%$ & a bs & $\%$ & a bs & $\%$ \\
\hline Since 2000 & 1 & 20.0 & 4 & 80.0 & - & - & 5 & 100 \\
\hline 1990s & 25 & 58.1 & 6 & 14.0 & 12 & 27.9 & 43 & 100 \\
\hline 1980s & 1 & 25.0 & 2 & 50.0 & 1 & 25.0 & 4 & 100 \\
\hline 1970s & 4 & 66.7 & 1 & 16.7 & 1 & 16.7 & 6 & 100 \\
\hline 1960s and prior & 3 & 75,0 & 1 & 25.0 & - & & 4 & 100,0 \\
\hline
\end{tabular}

Table 6: Year of Mall Opening and Urban Social Development

In our survey of shopping malls we identified seven different types:

\begin{tabular}{|c|c|c|c|c|}
\hline & \multicolumn{2}{|c|}{ Frequency } & \multicolumn{2}{|c|}{ Video } \\
\hline & abs. & $\%$ & abs. & $\%$ \\
\hline Shopping Strip & 15 & 24.2 & 11 & 73 \\
\hline Passage Type & 14 & 22.6 & 8 & 57 \\
\hline Centre-oriented & 10 & 16.1 & 6 & 60 \\
\hline Low-standard & 8 & 12.9 & 2 & 25 \\
\hline Open-air & 6 & 9.7 & 2 & 33 \\
\hline Mixed & 1 & 1.6 & 1 & 100 \\
\hline $\begin{array}{l}\text { Railway Station-centre } \\
\text { Other }\end{array}$ & $\begin{array}{l}4 \\
4\end{array}$ & $\begin{array}{l}6.5 \\
6.5\end{array}$ & $\begin{array}{l}4 \\
1\end{array}$ & $\begin{array}{l}100 \\
25\end{array}$ \\
\hline Total & 62 & 100 & 35 & 56.5 \\
\hline
\end{tabular}

Table 7: Shopping Types With and Without Video Surveillance

Table 7 shows a clear dividing line between shopping malls with and without video surveillance. All railway station centre types have video surveillance. The second most common type of mall with video surveillance - and also the most frequent mall type - is the shopping strip, laid out like a street with shops right and left. The passage type and the centre-oriented type have considerable surveillance potential. About 2/3 of them use video surveillance. Up to $1 / 4$ of the low standard mall type and $30 \%$ of the open space mall type have video surveillance. The absolute star in video surveillance coverage (100\%) is the new type of shopping mall inside the train station. This is due to the underlying security concept of the main business actor in this area, the railway corporation. In order to make the station space more attractive to customers and shop owners, stations have undergone substantial modernisation over the last decade. It appears that video surveillance was employed not only to monitor and manage transportation processes, but also to rationalise the maintenance of the building infrastructure. We will come back to this point later.

\section{Conclusion}

What about the ecology of surveillance? It turns out that there is more video surveillance in eastern Berlin, in large surface, newly built shopping malls, those close to urban mass transport, those oriented to larger catchment areas and developed either as shopping strip, passage or centre-oriented types. Smaller malls and less standard malls are less likely to apply video surveillance. In other words, anyone who does not want to be observed by video cameras 
should not frequent large shopping malls near urban mass transport stations. He or she should shop in nearby neighbourhood shopping malls.

However, a number of exceptions make it impossible to identify a consistent pattern of video surveillance. Some older neighbourhood malls have video surveillance systems, while some large newly built super-regional centres do without video surveillance systems in publicly accessible space. This leads to the conclusion that there is no common knowledge or strategy on how and where to implement CCTV. We seem to be in the middle of a process of testing, experiencing and discovering CCTV for use in Berlin shopping malls.

The fact that large shopping malls offer a broad spectrum of products and services makes them attractive to many visitors. Their appeal is augmented by the ease of access by urban mass transport and car. High rates of visitors can be expected. Such shopping malls represent a high surveillance potential. We may well find that this favourable constellation can be used for still unexplored surveillance options. In the worst case scenario, we have to admit that shopping malls can be used as launching grounds for important surveillance activities. And because malls with video surveillance are found at strategic places in urban structure, they are - planned or not, intended or not - building blocks of an emerging ecology of surveillance. Here we also need to consider something suggested by scholars of urban history: shopping malls may turn out to be focal points of urbanity (e.g.: Rybsczynski, 1995). Certainly large shopping malls have been successful. Even today they are far from the notion of simple "transit sheds" within everyday infrastructure. Whether we are more optimistic or more pessimistic about the surveillance impact, there is doubtlessly considerable potential. But how is this potential being exploited? We need to analyse how the surveillance system works inside the shopping mall and how its operators observe.

\section{Organisation of social control}

Before exploring the micro-level of the observation order inside the shopping mall, we first need to introduce some basic architectural details of shopping malls to provide some insights into the spatial arrangements of potential observation and social control. We also want to explore the modes of urban social behaviour that can be realised inside shopping malls. Here we look at the code of conduct expected of visitors. Some malls display written house rules that serve as internal social norms for judging customer behaviour. Together, the spatial order and code of conduct influence the interaction and observation modes of visitors, shop owners and control staff.

\section{Some basic architectural details of shopping malls}

According to our survey, the most frequent type of shopping mall is the shopping strip. A large rectangular building is divided into three parallel sections where the middle one serves as street or urban plaza containing plants, some water, benches and chairs. Shops and restaurants are on the left and right. Cafes and restaurants tend to be located on the upper floor, with shops for durable goods on the ground floor and food retailers (supermarkets and specialised food shops) in the basement. The entrance and rear house the largest retailers, the most attractive places to 
shop or to have a drink, etc. These anchor shops and cafés animate people to enter the mall, and create more shopping potential.

The shopping mall building of today is covered by a large roof made of glass and steel, lending a quasi-Mediterranean charm. The building contains several floors that can be reached by elevator, staircase or escalator. Overall one has the sense of walking through a transparent, naturally lit building, protected from outside environmental constraints. The architectural arrangement of shops, restaurants, cafés, cinemas and service facilities is complemented by decorations of seasonal shopping. There are benches for resting. Café restaurants are arranged for optimal people watching. Visibility of products and people is a must.

The observation structure given by this arrangement borrows heavily from the arsenal of panoptical knowledge. If we compare the architectural form of a shopping mall with that of a prison, there is an astonishing degree of similarity (see pictures below6). The visitor can nearly see everything - shops, restaurants, people - by walking around or viewing the comings and goings. Retailers, on the other hand, have close contact only to consumers who have entered the shop. Some scholars see the shopping mall as a kind of consumer paradise: "The subtext of the mall is mostly the message: shopping = heaven on earth" (Danesi and Perron, 1999: 196). But what about the shopping mall as part-time consumer prison? Here we are also considering the (less visible) surveillance infrastructure that permits direct and second order observations ${ }^{7}$ by the security staff. Video cameras are increasingly part of the modern shopping mall. They are situated at strategic points, near the entrance, crossroads, or intersections inside the mall, guaranteeing that the whole transit space, where people move, is under surveillance. According to business models for most shopping malls, the centre management does not monitor inside shops or restaurants. There are, however, video surveillance devices inside shops, particularly of big retail chains. There might also be video surveillance inside the car park. Quite often the centre management runs the latter as an additional business activity.
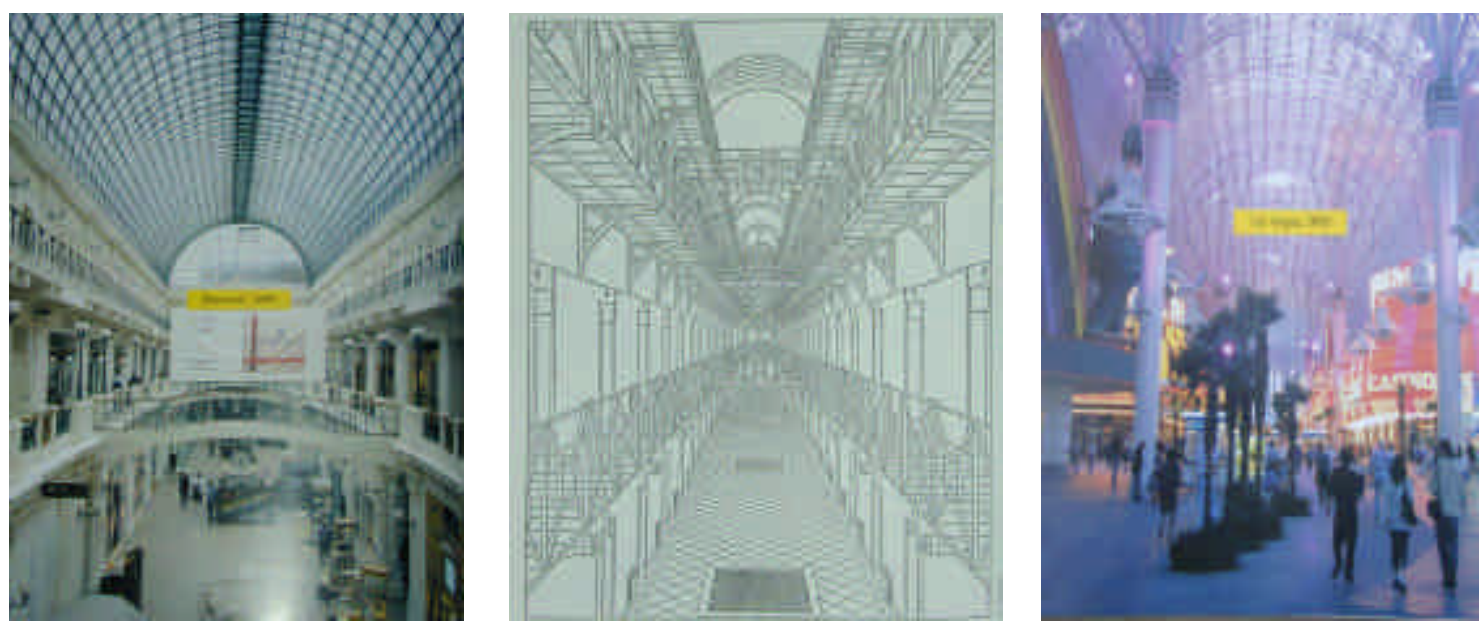

Left to Right Prison Germany; Passage Moscow, 1893; Shopping Mall Las Vegas, 2000

\footnotetext{
6 Cf. Project on the City 2 (2001); J.Geist (1969)

${ }^{7}$ Observation done by security managers e.g. observing how the security staff observe the consumer.
} 


\section{House rules}

Around $3 / 4$ of all Berlin shopping malls with video surveillance display written house rules to inform the visitor of the behavioural norms expected inside the private but publicly accessible space. Only around $29 \%$ of all malls with video surveillance, however, inform visitors of this fact. House rules concentrate on the regulation of everyday visitor activities - no loitering, no eating, no alcohol. Pets need to be kept on a leash, photos are allowed only by management permission, weapons are prohibited. House rules are a code of conduct to screen prospective visitors. Order is maintained by securing obedience to these rules. House rules can be understood as instruments to ensure behaviour that is only slightly but, however, significantly different from behaviour practised in the outer urban world. They are soft supplements to the architectural code of the shopping mall, which too is distinctive from the appeal of the outer world. In this way, the architectural code, as part of a certain sense of place (Jackson, 1994), may provoke ritualised behaviour due to the shopping malls' central message - inside a consumer paradise or a part-time prison. House rules protect the ritualised shopping exercise.

At the same time, we found that when some of the rules were broken (people hanging around, sitting and watching without consuming anything), nothing happened. Perhaps the control staff was not strict in applying rules that seemed widely unknown by the public. During our visits to shopping malls, we never saw anybody reading them. Only those rules that the management wants the customer to know are posted at the main entrances as large symbols. Besides these explicit house rules, there are latent rules that prevail inside the building. A consumer can feel what is desirable and undesirable behaviour. Nevertheless, the posted house rules serve to legitimate the actions of the security guards - who, in turn, have the latitude to define a behaviour or situation as deviant on a case-by-case basis dependent on whether it is regarded as disturbance or not. Shopping mall managers are keen to attract people and it seems that they tolerate much behaviour outside of the rules. Even the non-buying visitor or one whose behaviour is slightly off has value for the shopping mall business as potential consumer in the eyes of other mall visitors. Thus every visitor becomes part of the stage of the consumerism spectacle and - as told by a centre manager - part of the social control potential. The more visitors, the greater the social control of behaviour.

Were house rules strictly applied? We observed a relatively low level of staff intervention. In only two cases did we see that people who were smoking cigarettes were asked to extinguish them. Two cyclists were stopped from riding into the shopping mall. On the other hand, all kinds of people sitting around for extended periods - alone or with others - were not bothered. We had the sense that the control staff are generous and permissive. Nor did the staff inside the control room seem inclined to enforce the house roles very strictly. There was one exception. Understandably, past criminal acts heightened the alertness of security workers, who were then more likely to intervene.

\section{Systems and practice of video surveillance}

The two systems described here (centre A and centre $\mathrm{B}$ ) are based in two large shopping malls in Berlin (A 30,000 $\mathrm{m}^{2}$, B 40,000 $\mathrm{m}^{2}$ ). Both malls are classified as regional centres - as strip malls 
- with a mixed shop structure. They are located close to stations of public transportation. The main entrance is placed at a high street. The social structure of the area is basically stable in both cases.

The number of cameras and monitors varies considerably. System A has 86 cameras on 70 monitors, while system B has 33 cameras on 23 monitors. Both of the systems have two main monitors to which all cameras can be switched. One of the main monitors shows the image from the camera pointing at the car park exit. This image is permanently recorded. The second monitor represents the actual work monitor where images from different cameras in the mall can be switched on and occasionally recorded. As site A is smaller and older in construction than site $\mathrm{B}$, we find a still increasing number of cameras at shopping mall $\mathrm{A}$ and a more strategic complete - coverage at B. Strategic coverage means that cameras are pointed toward selected areas in the mall such as main entrances, escalators, elevators, delivery court and delivery ramps. Only some cameras can be turned or zoomed. The different modes and underlying concepts of video surveillance are partly related to the differences in architecture and spatial organisation of the malls. Shopping Mall A was built in the 1960s, when video surveillance was not available. The spatial organisation of $\mathrm{A}$ is reminiscent of a department store; the dense organisation of shops and services makes orie ntation difficult and demands many cameras. Shopping Mall B, in contrast, was erected in the 1990s and represents a clearly structured strip mall with distinct lines of access and excellent visibility.

\section{Objectives of the CCTV systems in sample sites as een by managers and operators}

According to centre managers, the main objectives of the systems are to prevent crime (mostly theft and vandalism), to support prosecution, and to "guarantee the safety of the customers". It is not always clear what is meant by 'customer safety' - from crime, accidents, disturbances, or a bit of everything? The analysis of most statements shows that it is a vague expression, without specific content except for the assumption that customers do feel threatened and expect that something has to be done to ensure their safety. The central issue seems to be the satisfaction of a presumed individual need for safety. Centre management is interested in providing a general feeling of pleasure and convenience to the public, especially to potential consumers/visitors and to shop tenants. The public wtion of video surveillance as a means to prevent crime seems to meet that goal best. At the same time, management does not want customers to know that they are under surveillance because they think this could inhibit ptential consumers from feeling at ease in the mall.

The technical or security managers mostly agree with the centre managers. They more often cite objectives of property management: e.g. guarantee of workflow, cleanliness and monitoring the function of technical devices (e.g. elevators, doors, escalators). One security manager admitted that video surveillance can also be used to reduce staff.

The operators, when asked about the objectives of the video system, repeat the statements made by management: "prevention of crime, to make citizens feel that something is done for their safety in the mall", or even "we are responsible for the customer". All are convinced that the 
video system is of great help in their work and are grateful for the system. In contrast to other interviewees, they have a very generalised notion of the objectives of their work. They see their task as "problem solving" whenever something disturbs the normal process of the shopping mall.

During our observations of daily routines, it became obvious that the above mentioned objectives of video monitoring systems are only part of the actual everyday objectives and tasks in the control rooms. The aim of the daily routine is to prevent trouble and to resolve disturbances, wherever they occur. Focused surveillance is neither intended nor feasible. Social control aspects seem to be a by-product. During the shifts, most attention is clearly given to handling fire alarms and other alarm systems. Sometimes video control and other alarm systems are used in combination. In some malls, for example, video systems are used to check spaces or to support technical services in case of technical alarms.

In conclusion, the objectives to employ and use video-surveillance are shaped by the different expectations and practices of the actors involved. Managers emphasise the need to ensure a safe and comfortable environment, to prevent crime, to maintain a proper workflow. They also state their hope to save money by substituting staff with technology. Operators partly share this overall attitude. However they emphasize the rationalisation aspect of CCTV. They also argue that in practice video surveillance is seen as one technological device among others to support the multitude of tasks inside the "control room." The closer the interviewee is involved in the everyday practice of video surveillance, the more he or she refers to facility management as an important aspect.

By analysing the systems and their applications, in the next section we will turn to the extent to which these objectives are pursued and can be achieved.

\section{Organisation of work within the control room}

\section{Workplace and equipment}

When exploring the history and everyday work practice of the systems, we realised that the root of video surveillance in German shopping malls is in fire prevention and property management rather than in social control. This could be one reason for the fact that control rooms are mostly separated from the main mall - the control room would not be jeopardised by a fire in the mall.

Although the dominant video surveillance monitors occupy the most space in the control room, there are a lot of other security devices such as alarms, telephone, radio, intercom, mobile phones, also PCs and PA systems for announcements and music. The design of the control rooms is generally dominated by technical equipment. There are almost no personal objects except an obligatory (male) calendar or poster with scantily-clad women. In one room we found a tiny flower, which was watered by every new shift. Most rooms have a shelf with files and a place to make coffee if there is no separate kitchen. 
In general, each shopping centre has only one monitor workplace for one person, who is responsible for the monitors, control of the cameras and the recording devices, as well as all alarms and communication systems.

As the 'nexus of all information,' the control room is connected to its environment by a number of links - communication and information devices. We noted the following:

- radio or telephone link to the security patrol in the mall and to facility staff in the centre (technical and cleaning service)

- cell phone 'always carried': all shops have an emergency number to inform security in case something happens

- emergency linkage to parking ticket dispenser and car park entry/exit

- elevator emergency alarm

- fire alarm systems, connected to the fire station

- entry alarm systems

- direct telephone lines or radio linkages to maintenance service, activated in case of an alarm

Rarely is mall security in touch with the police (no privileged links), who sometimes ask for tapes or digitally recorded material for their data files. But this does not happen very often (see Frequencies below p. 341).

These multiple linkages make it clear that many sources of information impact the work of the observer in the control room which really is the 'nerve centre' of the shopping mall. It is the place where incoming information needs to be handled and managed and where if necessary decisions are made immediately. The CCTV-system represents one information source besides others.

A contracted security company runs both systems observed. The staff are divided into specialised operators and guards. Two modes of internal work organisation are applied:

- a strict division between video-operator and guard, and

- a more flexible mode where everyone on staff performs video work and patrolling according to internal arrangements and changing demands.

Usually two or three persons work per shift: one in the control room, one or two in the mall. If only two persons are working per shift, it sometimes happens that no one is inside the control room as both have to walk the mall. Most malls run three eight-hour shifts during the week and two twelve-hour shifts on the weekend. The co-operation- communication process between control room operator and security staff on tour is based on mediated (radio) interaction: the person in the control room directs the one in the mall where to go, while the one in the mall tells the one in the control room where to look (most common).

One of the basic rules for the operators is 'self-protection first'. Even the centre managers do not want them to take any risks: "We have to make sure that our detectives are not taking risks by getting overzealous about hunting [criminals]". We once witnessed the emergence of this 
'hunting fever,' when an operator tried to find a person who had left the centre. The operator commented on his search several times by quoting a slogan from a television ad : "Sooner or later we will get all of you".

Some of the operators gave us examples for a second set of 'rules of thumb':

- You have to be calm and you should not get tense, because being cramped makes no sense,

- You have to stay cool, for example when several things are happening at the same time

- "You need to stay alert and you have to work chronologically"

- "You have to be aware but calm"

A 'laid-back' attitude is more important and desirable than proactive efforts to detect irregularities. Aim of management is to have security personnel who can work with reserve: "We do not want to have the bouncer of the disco in this building"

The role of the operators is dependent on the organisational structure and the division of labour among the different sub-units. We discovered some difficulties and conflicts due to unclear role patterns.

The operators assume the role as deputy of the management for enforcing the house rules and preventing risks. But in practice they take on a quite complex (more mediating) role among centre management, in-house technicians, cleaning services, shop tenants, and different groups of customers. Thus operators represent the whole mall organisation to exterior actors, e.g.: the enforcement of house rules, the organisation of deliveries, work on tenant requests, etc. On the other hand, they also execute services for the management and help in the administration of other services: mail services, announcements, operating sound equipment. However there are quite a lot of conflicts to be managed which refer to the vague role they perform and most interesting to their central task - to maintain control. Just to name one example: When designers decorate the centre for different events, they disregard the demands of the video system. Cameras are partly covered by flags, plants, and advertising. "There are no arrangements between design and security. If something is disturbing us, we have to let them know and ask them to change it". Usually they do not.

According to our investigation, the CCTV system - meant to support the central business of crime prevention - is being used more as an supporting instrument for fulfilling additional operational tasks in the centre and as an instrument to define status and role, as a tool to demonstrate power and influence to the other services working inside the mall. The operators can show that they are able to observe and to control (CCTV even empowers to monitor the manager during his/her break).

\footnotetext{
8 All quotations are taken from interviews with security staff during field research in Berlin Shopping Malls (2002/2003). For more information see: http://www.urbaneye.net
} 
Their status can best be described as a mixture of almost-manager, police officer, protector, or simply colleague or subordinate employee. It is within this context that we need to look at the meaning of video surveillance technology related to their work. To a certain degree, they are the "masters of surveillance," and they have more knowledge of what is going on than do others. It appears that the video systems sometimes allow the security staff to decide situations to their advantage.

\section{Bad image - low wages- minorstatus}

It appears that the operators we met were well chosen and demonstrate certain extra qualifications. They must be able to resolve evolving conflicts in a moderate and communicative way. And they must be aware of the fact that they, too, are always under surveillance. As centre managers emphasise, "they need a lot of sensitivity", "they must be able to serve as contact persons with communication skills". When not satisfied with staff members, centre managers ask the security company for replacements. As a kind of quality management, one centre manager made clear, "The security staff is always under surveillance, they never know where the enemy comes from".

The security staff are placed in a difficult situation, master and servant at the same time. As master he or she has to instruct customers and visitors on what is allowed and what is not. As servant he or she has to do this politely, with considerable communicative competence and without the use of force. He or she is also responsible for the functioning of the various elements of the shopping mall. It seems fair to conclude that the work is valuable but not sufficiently compensated. During the interviews the operators mentioned that 'only' watching the screen is not regarded as 'real work' by others, or that "watching the screen means that you have nothing else to do". Watching the video is equated with laziness and may be part of the reason why this type of control work is undervalued. ${ }^{9}$

To overcome this conflict, some security workers try to heighten their status by distinguishing their work from other "stupid" security jobs. They do not want to be compared with a "porter" or "watchman." One operator describes his work as follows: "It is interesting but sometimes a little boring (especially at night). You always know what to do and you know your task, it is not as stupid as door-keeping. It is interesting because something is always happening".

\section{Observational work of sec unity staff}

\section{Tasks and practice}

By listing the tasks of the security personnel, it becomes clear that there is much more work to be done than enforcing house rules (Table 8, overleaf), and at most of the tasks it becomes obvious that work can be performed only if the control room operator acts as co-ordinator and the mall security guard as his agent.

\footnotetext{
${ }^{9}$ Perhaps this is part of the reason they emphasise the need to stay relaxed, and try to avoid watching the screen too closely.
} 


\begin{tabular}{|c|c|}
\hline Tasks in the control room & Tasks in the mall \\
\hline 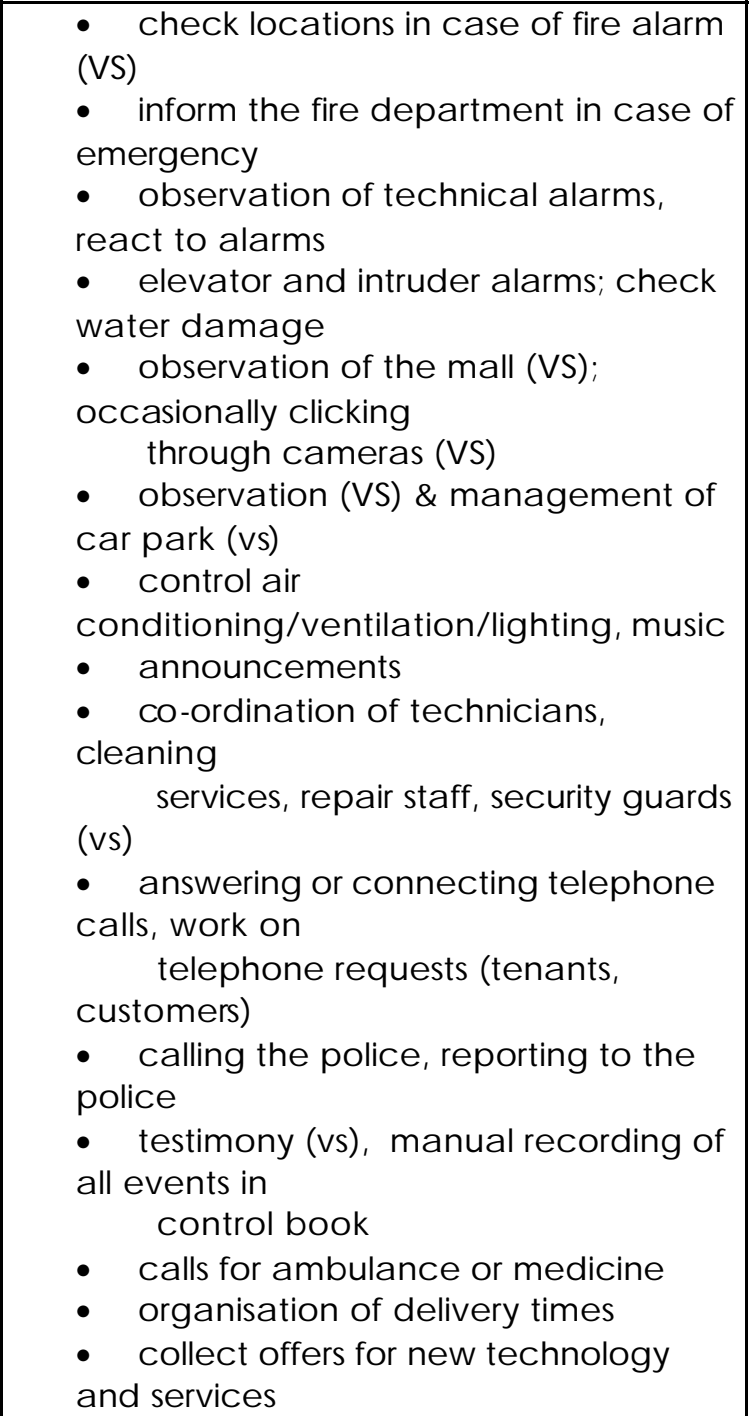 & $\begin{array}{l}\text { - } \quad \text { tours of inspection } \\
\text { - check locations in case of fire a la mm } \\
\text { - } \text { accompany repair workers; support } \\
\text { of technicians } \\
\text { - contact to shop tenants } \\
\text { - customer contact and assistance } \\
\text { - check garbage cans } \\
\text { - enforcement of house } \\
\text { - co-operation with shop detectives } \\
\text { - prevention of physical aggression } \\
\text { - intervention in brawls } \\
\text { - } \quad \text { testimony } \\
\text { - report to the police } \\
\text { - } \text { first aid } \\
\text { - errands for management or other } \\
\text { departments }\end{array}$ \\
\hline
\end{tabular}

Table 8: Tasks in the Control Room and the Mall (VS) = task ma inly conducted by the application of the video system (vs) = video system can occasionally be useful to support the task

Because the operator can see more via video (something like a bird's eye view), he or she is in a better position to co-ordinate action. ${ }^{10}$

The tasks conducted by the application of the video system constitute a smaller proportion of the work. But the number of tasks says nothing about their importance, frequency and duration.

Importance and meaning of different technological devices

While the video systems and especially their monitors are the most dominant feature in the

10 "Rather through CCTV supervisors are able to 'recontextualize' action" (Heath/Luff/Svenson 2002: 199) 
control rooms, greater importance is attached to fire alarms as the most important technology. According to one technician, "If it starts, the action is in here." The operator answers, "That is why we always need to caress the box." A fire alarm is the worst thing that can happen during a shift - to be avoided by all means, even by an emotional and symbolic or even magical' attention to this technology in the control room. We did not observe such a close relation to video surveillance technology, although it was underlined several times how useful it is to have the video system. However, during an actual alarm on the second observation day, all participants remained relaxed.

\section{Events and attention processing systems and practice during the shifts}

According to the operators the most frequent events are:

1. disturbances by technical alarms (elevator, escalator, etc.);

2. requests from car park or shop tenants;

3. unruly behaviour in the mall or car park (smoking, bicycles, roller blades, etc.).

Within a twelve-hour shift inside the control room, we identified a total of 51 events/actions. From these observed actions only 9 dealt with video surveillance (besides switching through the monitors from time to time), 18 with the management of technical alarms, 10 with telephone calls, 8 with car park affairs and 6 with additional services for the mall management. From 37 actions in another shift, 15 had to do with the management of the car park, 8 with technical alarms, 5 with video surveillance, 2 with telephone services and 7 with other additional services.

Taken together, we can distinguish five categories of actions (Table 9).

\begin{tabular}{|l|l|l|}
\hline Type of actions & $\mathbf{n}$ & \% \\
\hline management of tec hnical alams & 26 & 29.5 \\
\hline car park management & 23 & 26.1 \\
\hline use of video surveillance system & 14 & 15.9 \\
\hline additional senvices & 13 & 14.8 \\
\hline answering the telephone & 12 & 13.6 \\
\hline sum of actions & 88 & $\sim 100$ \\
\hline
\end{tabular}

Table 9: Distribution of different actions duning 20 hours of obsenvation

The proportion of tasks listed here was confirmed by further observations in other shopping malls.

The duration of the actions is usually short - around 1-3 minutes in cases of technical alarms or, in the case of targeted observation, a maximum of 15 minutes. Everyday work in the control room thus consists mainly of waiting for things to happen. Very few actions result from an observed unruliness on the video monitors. Accordingly, proactive observation of persons is not frequent. It does not seem to be easy to remain alert while nothing happens. Indeed, an operator's most important skill is to stay calm but attentive, over the entire shift.

\section{Types of operators and practices}

As mentioned above, operators are laid back' in their use of the video system. We could distinguish three different types of operators in dealing with the video system: 
- Type A: Does not look at the monitors except if requested to do so by telephone or in reaction to other information. Older and indifferent to the technology.

- Type B: Clicks from time to time (once in two hours) through the cameras without targeting certain people. Clicking almost never results in a deployment. Younger and inexperienced

- Type C: Focuses on certain places in the mall, seen as crucial, when there is time between other actions. Knows best how to handle the system. Middle aged, experienced and well regarded by colleagues

\section{Use of cameras}

We were surprised to observe the rare use of the video systems. Being asked when they do use the video system, some responded "if there is any time left...". The operators claim to watch the monitors "out of corners of their eyes", while doing other tasks. If something unusual is happening, they will go closer to an object and zoom in. The surveillance of the shopping mall is thus structured by a varying mixture of individual preferences and applications, together with organisational musts. During one shift, for example, the video system was used 9 times for these purposes, but only twice for a concrete suspicion (once initiated externally). Few deployments are caused by an observation; most are prompted by telephone calls, emergency alarms, etc.

In case of a conflict, the video system is used to protect the security guard: his or her deployment is recorded to counter unfounded accusations. Some security guards had been reported for slander or bodily harm. Their colleagues emphasise that the reports were unfounded. In one case the video record cleared the security guard ("Demonstrators attacked the guard and accused him of doing so."). Some operators regard the camera as a means of increasing their own safety.

Targeted observations were noted 13 times during 40 hours of observation. "Unruly behaviour" is the most frequent reason for targeting but constitutes less than 1/3 of such actions. Unruliness is defined as begging, smoking, brawling, and youngsters in the "wrong" place (e.g. car park at the top of the building). Although the actual cases of targeted observations are rare, it is worthwhile examining how the operators construct deviant behaviour. In four cases we can speak about a real targeted observation in the sense that the operator perceived somebody as a suspicious person. Only one of the targeted persons belonged to a minority ethnic group (Turkish). One should not, however, conclude that the dominant ethnic group is more suspect to the dbserver. One woman was targeted, and one group of teenagers.

Why they were suspicious to the observer? In the case of the Turkish man, he was probably observed because he was Turkish. In the case of the youngsters, it was probably because they were young. But we can not prove this impression with the observations alone. The group of youngsters, for instance, were in a place where they were not allowed to be. We do not have any evidence for the assumption that they would have been not targeted if they had been older.

In summary, the suspicions were locational (4) and behavioural (4), transmitted (2) and personalised (1). To be in the wrong place can, by the way, also be defined as "wrong" behaviour. 
These figures back up the findings of the qualitative interviews: deviant behaviour is regarded as unruly or being in a certain place. According to the interviews and the operators' statements during the observations, the findings of the observation confirm that they rather "monitor locations and behaviour, not persons."

In the interviews and in conversations during the shifts, however, the operators name certain groups of persons as rather suspicious: school children/teenagers, men, alcoholics, homeless and mostly foreigners, especially southern Europeans such as Turks or eastern Europeans such as the Romany (Gypsies), Poles and Romanians. "For example, a doorman informs me watch out, now some foreigners are coming in,' we know people who are conspicuous. Well, then we follow that person" (WS2).

Operators mostly describe situations where they can see "immediately" if there is a threat or not. "They come in with big empty bags, this is already suspicious, then they clear shelves in 'Douglas' [perfumery] or 'Kd' [drugstore]. They are four, two for the lookout, two to go into the store and to do the job. We have to catch them when they are trying to escape." In that case, the video recording serves as a safeguard for the security personnel.

All observers claim to be able to see when deviant behaviour occurs on the screen: "You can recognise them by their body language and by their behaviour. They are acting in a strange way. Well, experienced detectives can see that by the way those people look around. These are signs, conspicuous signs. You can learn about those things, but they are hard to explain. You have to experience it and to develop an ability for how to look at those persons." A manager, formerly a salesperson, argues similarly: "You immediately have a feeling if somebody is suspicious. Then you better keep an eye on him. You recognise it; those people behave different from others who are here for shopping. Those who have other intentions do not have a relaxed, clear and visible body language." (CM2).

Deviations are mainly defined as the intention to steal and the infringement of house rules. The operators claim to see when someone plans on committing theft: "You can see whether a customer will buy or not. The re are certain characteristics." "Certain behaviour is conspicuous and then you follow and watch that person." It does not seem to be easy to describe what makes a behaviour suspicious: "You can only guess if a person is suspicious by feeling and everyday experience". That seems to be one of the main reasons why video surveillance cannot be explained but only learned by doing. The operators have experience with favourite (critical) places, times (rush hour) and seasons (summer) for theft.

Despite their insistence that an experienced observer can distinguish criminals from innocent customers, the interviewees say it is becoming increasingly difficult because criminals do not behave like criminals anymore. "Times have changed (...) the thieves have adapted to the situations and locations, they come in with suits and ties, they work for criminal organisations (...) the common thief from caricatures does not exist anymore." Although it is doubtful that thieves ever resembled their caricatures, this statement, among others, shows even experienced operators have a hard time separating 'good' and potentially 'bad' visitors to the shopping mall. 
Operators also claim that the infringement of house rules is detected on video screen. "With time you develop the necessary look. For example if you are working at the desk and the monitor, there are some movements that should not be there, somehow your eyes are automatically pulled to the monitor." "You know which movements are normal and which are not." They list a number of examples: cars in the car park that drive in the wrong direction, people with bikes in the mall, groups in the mall, smoking, spitting or dogs without leashes.

"Taking photographs," which also violates most house rules, was described as problematic due to the fear of competitors and organised criminals, and regarded as a severe threat to the mall's interests. This was mentioned in several interviews and observed during the observations. Nonetheless we were rarely accosted for taking photographs for experimental reasons during our investigations. In only one mall was our action detected and sanctioned.

Enforcement of the house rules is also seen as a means to prevent crime. "The sooner you fight irregularities the less crime you'll have." "For that reason we are interested in breaking up groups that enter the centre, if there is any legal way to do so. The house rules say groups are not allowed." (!!) (In fact, this is not the case).

The operators' attention is caught explicitly by behavioural and locational deviations, implicitly by categorically constructed deviations. We do, however, need to point out one contradiction concerning the competence of the "experienced" observer in identifying a suspicious person. As we said, the observer constructs suspicion in a mode of information processing, where he or she compares a set of external indications with a concept of suspicious. Should external indications change because the professional criminal is well dressed, and can stay calm in critical situations? What does the observer really see? Research on criminal behaviour (Gladwell, 2002) shows that the ability to identify an individual's intention by looking at facial expressions is possible and can be trained. This seems to be a valid way to identify intentions. But it is unlikely that this can occur via remote video surveillance. The construction of deviant behaviour with the help of video surveillance is, we would argue, questionable.

\section{Frequencies}

Asked how often the security guards in the mall are deployed on an average day, the operators estimated "up to five times a day". During our observations we saw three to four deployments per shift. Deployment does not mean that the guards intervene in a criminal action, it can also be helping a person or taking care of a technical problem. Deployments "...with physical aggression [happen] up to five times a year," or "once in half a year".

Seldom does an operator observe a criminal action on-screen. "How often do we see a theft in action? Perhaps less than five times a year." The frequency of a crime caught on camera and especially on tape is low, and for that reason co-operation with authorities in terms of the exchange of video recordings is rare: "Once every three months maximum do the prosecution authorities ask for a tape as proof." Only once has a video recording been used in court during the five or six years since the video systems were installed in the two shopping centres. 
One of the most important instruments for enforcing house rules is the banning of a person or a group from the mall. According to the operators' statements, even this happens "every two or four weeks maximum" (A) or "three to four times during the last four months" (B).

\section{Impactscaused by potentiality}

Although the system is seldom used for the proactive monitoring of individuals, it is assumed that video surveillance has an impact. All interviewees expect and observe changes in behaviour due to video surveillance. Although we cannot prove that customers act differently when under video surveillance, the interviews and observations provided intriguing clues as to how the operators construct impacts.

One example can be found by looking at the reason behind the reluctance to post signs that the premises are under video surveillance. Most shopping malls with video systems have no signs indicating that video surveillance is in operation. From 35 malls with video systems in the publicly accessible space, only 11 have signs stating this.

Some statements are contradictory. On the one hand, the systems are meant to have a preventive mpact when people know they are being watched. On the other hand, the mall management does not want people paying too much attention to video systems because it is feared that customers will feel uncomfortable. "We were afraid that this could deter customers from entering the mall".

Asked whether customers might not feel safer knowing that the mall is under surveillance, most of the interviewees expressed their doubts, despite the claim that video surveillance increases customer safety. One of the interviewees said no to the question if customers know they are under surveillance: "No, that's camouflaged well. If they knew we are looking at them, they would never come back to the centre".

As for visitors, most of interviewees state that they behave differently when they know they are under surveillance. But they always emphasise that this is not unpleasant. "You pay more attention to your own behaviour, how you walk, how you look (...) you have the feeling you should behave differently. My colleagues say the same" (WS3). "You act differently because you always know there is an eye on you" (WS2). Feeling safer, more at ease, being on stage are perceived as positive outcomes of the systems. Thus it turns out that there is a dilemma in evaluating the impacts of CCTV and in deciding whether or not customers should be aware of the system.

The centre manager spells out the underlying assumption that those who have reservations about video cameras are potential suspects. "Only people with 'problems' (something to hide) will have doubts" (CM3) or "As a customer it is not a problem. As a thief it bothers me" (CM2). Here lies a further contraction: if innocent customers have nothing to fear why would the awareness of being observed deter them from visiting the mall?

This point aside, both management and staff assume that videos will deter criminals and customers alike. But according to the interviewees, there were no customer complaints about 
video observation in any of the malls studied. Quite the opposite. "They say they now feel somehow safer" (WS1). No matter how you look at it, video surveillance has impacts because it is expected to.

The symbolic capital of CCTV can also be used to convince suspects to admit to their deeds. The security guards use the widespread overestimation of the system by letting suspects believe that everything can be seen on videotape. 'We told them, 'if you want, let's watch TV until you recognise yourself and see what was happening. But perhaps you can answer our questions right now'. They all agreed without hesitation" (WS1). (The interviewee did not say whether the event was caught on video, but the probability seems very low).

At this point we have to admit to our limited knowledge on the exact repercussions on the potential of CCTV. The potentiality of video systems, however, seems to be sufficient to cause impacts. Here we recall the system of discipline and knowledge described by Foucault (Foucault 1978). Effects can also be regarded as a kind of self-fulfilling prophecy (Merton): the belief in the efficiency of the system makes it work, independent of the real use.

\section{Summary}

The video systems observed in Berlin shopping malls do not seem to be an efficient instrument of social control and exclusion. They are used more on demand for various operational purposes. The observation order in malls resembles that of a public transport system as observed in London by Heath, Luff and Svenson (2002: 198): "To a large extent supervisors are not concerned with identifying particular individuals, but rather with detecting actions and events which might disrupt the ordinary flow of passengers and traffic through the station."

The objectives publicly claimed by management - crime prevention and the like - could not be achieved because the everyday practice presents other tasks to the operators. The workplace, the personnel, their multiple tasks, their qualifications support more a reactive use of video surveillance than a proactive targeted observation of individuals, even if the equipment would allow for that. It is doubtful that the publicly stated objectives are the same as the internal ones. We must assume that those objectives are a part of an "impression (management) scenery" (Goffman 1990), while video systems are meant and used for other purposes involved with core business process of the mall.

However, these findings must not lead us to underestimate the potential of the systems and the fact that a new observation order is emerging. We need to remember the ecology of surveillance described above, which has demonstrated that a considerable degree of important urban places have CCTV installed. This could allow for the realisation of more strategic objectives of CCTV. Such systems are open for various purposes. It is easy to imagine that different actors will find out how to maximise the power of video surveillance by scanning and profiling consumers or other individuals. In this sense it may turn out that the CCTV infrastructure of Berlin shopping malls can be characterised best as test-beds - open for various applications. There are, however, obstacles to this in the form of data protection concerns and the lack of political and 
economic support to go further (tied of course to financial constraints). Finally, as shown in our study, the social practice in everyday life continues to resist one-dimensional expectations of the technological possibilities of CCTV.

\section{References}

Benjamin, W. (2001) Gesammelte Schriften V. Das Passagenwerk . Frankfurt/M.: Suhrkamp

Berlin (2002) City 21 - Bündnis für lebendige Innenstädte, September 2002.

Danesi, M. and Perron, P. (1999) Analyzing Cultures: An Introduction and Handbook. Bloomington, Indiana: Indiana University Press.

Falk, B. (ed.) (2003) Shopping Center Report 2003. Starnberg: Institut für Gewerbezentren

Foucault, M. (1978) Überwachen und Strafen:Die Geburt des Gefängnisses. Frankfurt/M.: Suhrkamp

Geist, J. (1979) Passage:. Ein Bautyp des 19. Jahrhunderts. München.

Gerlach, T. and Jungeblodt, C. (2002) 'Die Schattenmänner', Ver.di Publik 11, November: 12-13

Giddens, A. (1987) The Nation-state and Violence: Volume Two of a Contemporary Critique of Historical Critique of Historical Materialism. Cambridge: Polity Press

Gladwell, M. (1996) 'The science of shopping: A reporter at large'. http://www.gladwell.com/1996/1996_11_04_a_shopping.htm

Gladwell, M. (2002) 'The Naked Face: Can you read people's thoughts just by looking at them?' http://www.gladwell.com/2002/2002 0805 a face.htm

Goffman, E. (1990) The Representation of Self in Everyday Life.

Graham, S. and Marvin, S. (2001) Splintering Urbanism: Networked Infrastructures, Technological Mobilities and Urban Condition. London, New York: Routledge.

Heath, C.C., Luff, P. and M. Sanchez Svensson (2002) 'Overseeing organisations.' British Journal of Sociology 53(2): 181-203.

Jackson, J.B. (1996) A Sense of Place, a Sense of Time. New Haven, London: Yale Un iversity Press.

Lyon, D. (2001) Surveillance Society: Monitoring Everyday Life. Buckingham: Open University Press.

Marx, GT. (2002) What's New About the "New Surveillance”? Classifying for Change and Continuity.' Surveillance \& Society 1(1): 9-29 http://www.surveillance-and-society.org/articles1/whats new.pdf

Chung, C.J., Inaba, J., Koolhaas, R. and Leong S.T. (eds.) (2001) Project on the City 2: Harvard Design School Guide to Shopping. Köln: Taschen.

Rybsczynski, W. (1996) City Life:Urban Expectations in a New World. Reykjavik: Scribner Book Company

Schubert, C. (2003) Fünf Pfund für jede Fahrt in die Innenstadt. London macht von Februar an mit der Erhebung von Einfahrtsgebühren Ernst.' Frankfurter Allgemeine Zeitung, 28 January 2003, 23:13 
Senatsverwaltung für Stadtentwicklung, Umweltschutz und Technologie, Berlin (ed.) (1998) Sozialorientierte Stadtentwicklung. Gutachten im Auftrag der Senatsverwaltung für Stadtentwicklung, Umweltschutz und Technologie. Berlin: Kulturbuch-Verlag

Stanley, J. and Steinhardt, B. (2003) Bigger Monster, Weaker Chains: The Growth of an American Surveillance Society. New York: American Civil Liberties Union.

Täubner, M. (2002) 'Sheriff, Fahrer, Regenmacher. Private Sicherheitsdienste bilden erstmals Lehrlinge aus Die Zeit, 28 November 2002, 49: 84 